\title{
Presentation Modality and Source Monitoring During Management Inquiry: Effects on Auditors' Reliability Judgments
}

\author{
Kelly F. Gamble \\ Assistant Professor of Accounting \\ College of Business Administration, University of Alabama in Huntsville \\ Department of Economics, Accounting and Finance \\ 301 Sparkman Drive, BAB 333, Huntsville, AL 35899 USA \\ Tel: 1-256-824-6617Ｅ-mail: Kelly.Gamble@uah.edu
}

Received: January 9, 2013

Accepted: January 28, 2013

Online Published: January 30, 2013

doi:10.5430/afr.v2n1p73

URL: http://dx.doi.org/10.5430/afr.v2n1p73

\begin{abstract}
An experiment was performed to determine whether the presentation modality of evidence affected auditors' accuracy in identifying the sources of that evidence (i.e., source monitoring) and their subsequent judgments of evidence reliability. Participants were provided with conflicting explanations for a material increase in a fictitious client firm's gross margin. The explanations were presented in either the same (both visual) or mixed (one visual and one auditory) modalities. The sources of the explanations had either the same (both high) or mixed (one high and one low) levels of credibility. Results indicate that auditors who received evidence in mixed presentation modalities were more accurate in identifying the sources of that evidence. Also, auditors with more accurate source monitoring judged evidence obtained from a less-credible source to be of significantly lower reliability than did auditors who were not as accurate in identifying evidence sources. These findings suggest that auditors' judgments of evidence reliability may be influenced by the sensory modality by which evidence is perceived. Also, post-hoc analysis indicates that taking notes may improve auditors' source monitoring accuracy when evidence is perceived via an auditory modality.
\end{abstract}

Keywords: Audit, Presentation modality, Source monitoring, Reliability

\section{Introduction}

Auditors often have no control over the format in which evidence is provided to them. The format of the evidence determines the presentation modality, i.e., the method or sense through which the auditor perceives the evidence (Johnson et al., 1993). For example, when performing management inquiry, the format and presentation modality of the response will depend upon management convenience and/or the circumstances under which the inquiry was made. Another issue with regard to the use of management inquiry as an audit procedure is that the auditor who is responsible for making a decision may not be the individual who had direct contact with management. Rather, the decision-maker may have to rely upon documentation prepared by the member of the audit team who received the information from management.

The auditor must assess the reliability of all evidence, regardless of its format and presentation modality. The source of evidence is weighed heavily in assessing its reliability (PCAOB, 2010). For this reason, the auditor's accuracy in matching evidence items to their sources is critical. Failures in this matching process may produce inaccurate reliability assessments which can result in over- or under-auditing of the financial statements. Thus, identifying factors which may affect an auditor's reliability assessments can help increase audit efficiency and effectiveness, two primary ingredients of audit quality (Ashton and Ashton, 1988).

Several studies have provided evidence that auditors are sensitive to source when evaluating the reliability of evidence (Bamber, 1983; U. L. Anderson et al., 1994; Rebele et al., 1988). However, few researchers have addressed the fact that auditors obtain evidence in various formats (memoranda, email, oral communication), and media (paper, computer, telephone), and via different presentation modalities (visual, auditory). In the case of management inquiry, auditors may obtain evidence via visual, auditory, or mixed modalities, depending upon the response format chosen by management. One known study has investigated the effect of presentation modality on auditors' decision-making. 
The author found significant differences between the judgments of auditors receiving evidence via auditory, visual, and mixed modalities (Ricchiute, 1984).

When combined with the hierarchical structure of the audit team, the management inquiry audit procedure introduces another level of uncertainty into the evidence evaluation process. The decision-maker must evaluate the credibility of two sources: that of both client management and the audit team member who prepared the documentation. In these situations, Haynes (1999) found that auditors may compensate for this additional uncertainty by focusing on the credibility of the audit team member as opposed to the diagnosticity of the evidence under review.

Recent technological advances have made the auditor's task of evaluating evidence reliability more difficult. In addition to performing traditional audit procedures such as inventory observation, the modern auditor also collects and evaluates evidence obtained from conference calls, video conferencing, and text messages (Gamble, 2010). Corporate email is also gaining importance as a source of audit evidence (Debreceny and Gray, 2011). Common situations can increase the complexity of the auditor's evidence-to-source matching process. On a conference call, for example, several people speaking at the same time may impair the auditor's ability to discern exactly who said what. This is a significant issue for the member of the audit team who is responsible for documenting evidence in the working papers, particularly when evidence items are obtained from sources of varying credibility levels (Gamble, 2010). Further, research has shown that the completeness of the working papers that are reviewed by the engagement partner depends upon the audit senior's memory for the evidence gathered during the audit (Ricchiute, 1999).

The term 'source monitoring' describes the process of making attributions about the origins of memories, knowledge, and beliefs (Hashtroudi et al., 1989). Accurate source monitoring is critical for cognitive processes such as judging credibility and monitoring past actions (Johnson et al., 1993), and research has found that presentation modality affects source monitoring accuracy. For example, individuals are less accurate in their source monitoring when all evidence items are presented via one modality than when the items are presented via mixed modalities (Lindsay et al., 1991). In an audit setting, poor source monitoring would lead the auditor to incorrectly identify the source of evidence items. In cases where the sources in question are of differing levels of credibility, the auditor's assessment of evidence reliability would be impaired and could affect audit quality. The auditor's ability to accurately assess the reliability of evidence determines the effectiveness and efficiency of the audit (Knechel and Messier, 1990).

The current study investigates whether presentation modality can affect auditors' reliability judgments by influencing their ability to correctly identify the sources of audit evidence. In an experiment involving 91 practicing auditors, the study examines whether presenting evidence in mixed (visual and auditory) modalities, as opposed to a single (visual) modality leads to: (1) an increase in auditors' accuracy when identifying sources of evidence; and, (2) differences in the reliability judgments of evidence when obtained from sources (audit team members) having different credibility levels. Additional analysis was performed to determine whether taking notes while receiving information via the auditory modality can affect source monitoring accuracy.

The results of this study indicate that auditors who received evidence in mixed presentation modalities were more accurate in identifying the sources of the evidence items. In addition, auditors displaying higher source monitoring accuracy assessed the reliability of evidence obtained from a less-credible audit team member to be significantly lower than did the auditors who were not as accurate with their source monitoring. In addition, post-hoc analysis indicates that note-taking may improve auditors' source monitoring accuracy when receiving information via the auditory modality.

These findings contribute to the literature in several ways. First, advances in cognitive psychology allow for the testing of directional hypotheses with regard to the effects of presentation modality on auditors' reliability assessments. Consistent with Ricchiute (1984), the current study provides evidence that presentation modality can influence auditor decision-making. The results of the present study also extend Ricchiute (1984) by predicting and finding that receiving multiple evidence items via a single sensory modality would affect auditors' evidence reliability judgments by impairing their source monitoring processes, resulting in the misattribution of evidence from one source (of lower credibility) to the other (of higher credibility).

Third, for his mixed-modality manipulation, Ricchiute (1984) provided one set of evidence via both auditory and visual modalities. Thus, his participants received the evidence twice. In the current study, each set of evidence was provided once, either via auditory or visual modality. Therefore, the mixed-modality manipulation used in the present study more closely resembles audit practice. In addition, the modality effect identified in this study may have further implications for the quality and completeness of working-paper documentation, and may, thus, ultimately influence the engagement partner's decision-making. 
Finally, these results also provide support for the findings in Haynes (1999). The auditors in the present study appeared to focus more on the characteristics of the audit team members, and less on the evidence itself, when evaluating evidence reliability. The evidence items provided to the participating auditors was not sufficient to explain the issue under investigation, but the participants seemed to base their reliability judgments on the presumed credibility of the audit team member providing the evidence. Consistent with Haynes (1999), this result implies that evidence diagnosticity was not weighed heavily when evaluating its reliability in a management inquiry context.

\section{Background and Hypothesis Development}

\subsection{Source Credibility, Evidence Reliability, and Management Inquiry}

Audit Standard (AS) No. 15 requires auditors to perform audit procedures to obtain sufficient (enough), appropriate (good quality) evidence to provide a reasonable basis for an opinion. For evidence to be appropriate, it must be both relevant and reliable. In providing guidance on the factors that affect the reliability of evidence, the standard states that both the nature and the source of evidence must be evaluated along with the circumstances under which it was obtained (PCAOB, 2010).

Evidence acquired from independent sources outside of the client firm is considered to be more reliable than evidence obtained from within-company sources (PCAOB, 2010). While client management lacks the objectivity of an independent third-party source, its entity-specific knowledge makes it an invaluable source of information (Haynes, 1999). In some cases, such as when the auditor seeks to explain an unexpected fluctuation, management may be the only source (U. L. Anderson et al., 1994; Wright and Berger, 2011). Results of management inquiry do not, by themselves, constitute sufficient, appropriate evidence. The auditor is required to corroborate management's responses by some other means (PCAOB, 2010).

A well-established stream of experimental literature has examined whether auditors are sensitive to the credibility of the sources of evidence when making judgments on evidence reliability. The credibility manipulations which have produced the most consistent results are those defined in terms of source competence. The results of these studies have indicated that auditors are sensitive to source credibility when it is operationalized as training and experience (U. L. Anderson et al., 1994; Bamber, 1983; Rebele et al., 1988) technical ability (Hirst, 1994), or prior work performance (Margheim, 1986). Specifically, these studies found that auditors placed more (less) weight on evidence obtained from a source described as having a higher (lower) level of competence.

Most source credibility studies have focused on sources external to the audit team. For example, Rebele et al. (1988) and U. L. Anderson et al. (1994) found evidence that auditors recognize differences in the training and work experience of client employees. Hirst (1994) defined competence in terms of the industry specialization (within or outside of the client firm's industry) of a third-party source. However, as noted by Bamber (1983), audits are conducted by audit teams characterized by a hierarchical structure and division of labor. The division of labor inherent in the audit team structure means that in-charge auditors must frequently evaluate evidence that was obtained, and/or documented, by another member of the audit team. Thus, the capabilities of the team member who prepared the evidence must be assessed in order to determine the extent to which their work can be relied upon. By performing his experiment within this context, Bamber (1983) was able to 'focus on a more realistic setting of the audit judgment process' (p. 396-97).

The management inquiry audit procedure can be described as containing both source- and evidence-related uncertainties (Knechel and Messier, 1990; Haynes, 1999). That is to say, the procedure requires the decision-maker to evaluate multiple levels of source credibility (i.e., the credibility of both client management and the audit team member) in addition to the characteristics of the evidence itself. Haynes (1999) found that auditors were more sensitive to source characteristics than they were to evidence diagnosticity in the context of management inquiry. These results imply that auditors may cognitively adjust for the additional uncertainties inherent in the management inquiry procedure by focusing more on source characteristics than they do on evidence characteristics (Haynes, 1999).

\subsection{Source Monitoring and Presentation Modality}

The source monitoring framework addresses the general question of how people differentiate between memories from different sources (Lindsay and Johnson, 2000). The source monitoring process is invoked when we try to remember where and when an event occurred, who was involved, the medium of presentation, and/or the sensory modality through which an event was perceived. The primary assertion of the source monitoring framework is that people do not directly retrieve memories by tags or labels (Johnson et al., 1993, Lindsay and Johnson, 2000). For example, we do not categorize our memories as 'things that happened at school' or 'things that Mike said yesterday.' 
Instead, the thoughts, feelings, and images that form our memories are associated with particular sources. We then infer the sources of memories from their perceptual, semantic, and affective content. Most of our source attributions are made rapidly, unconsciously, and with little effort (Lindsay and Johnson, 2000).

Source monitoring, and failures in source monitoring, influence our memories for events and impact the development of our knowledge, opinions, and beliefs (Johnson et al., 1993). For example, assume that a woman reads the headline 'Alien Space Ship Lands in New York City' while standing in line at a grocery store. The next day, she overhears some co-workers discussing extra-terrestrial beings. As she remembers reading the headline about the alien space ship, her opinion on the topic of extra-terrestrials will likely depend, in part, upon whether she recalls the source of the headline to be a gossip magazine or a well-respected news journal.

Accurate source monitoring depends upon the combination of the individual's judgment processes and the contextual information (memory characteristics) established when the memory is initially formed. Examples of the contextual information associated with specific events include: sounds, colors, spatial information (e.g., where one object is relative to another), temporal information (e.g., time of day), and affective information (i.e., emotional reactions) (Johnson et al., 1993). Because source monitoring is based on the contextual information stored in memory as an event occurs, source monitoring accuracy depends upon the quality of that information. Anything that prevents a person from perceiving the contextual information associated with a particular event will reduce his or her ability to encode potentially relevant source information (Johnson et al. 1993). For example, stress or divided attention may interrupt perceptual processes, which can result in poorly encoded contextual information (Jacoby et al., 1989; Kelley and Lindsay, 1993). In addition, anything that increases the probability of one event becoming blended with another event will reduce the amount of source information stored in memory and impair source monitoring accuracy (Johnson et al., 1993).

People are more likely to confuse sources of memories that are similar in perceptual characteristics and semantic detail (i.e., words and phrases contained in a message) (Lindsay et al., 1991). One perceptual characteristic that may vary across memories is the sensory modality (e.g., auditory, visual, or mixed) through which information is perceived. Penney (1989) proposed a 'separate streams hypothesis' which stated that human information processing mechanisms are specific to either auditory or visual stimuli. She also wrote that the streams had distinct properties and represented information in their own unique ways (Penney, 1989).

According to Penney (1989) the processing differences between the separate auditory and visual streams affect memory performance and result in 'modality effects.' Studies on modality effects have found that auditory presentation results in superior recall of the last few items in the list (i.e., a recency effect) (Corballis, 1966; Laughery and Pinkus, 1966) and that auditory items are retained better than visual items (Kirsner and Craik, 1971; Murdock, 1968). Several studies support the separate streams hypothesis by providing evidence that memory improves when multiple presentation modalities are used (Frick, 1984; Martin, 1980; Mousavi et al., 1995; Tindall-Ford et al., 1997).

The roles that source monitoring and presentation modality may play in accounting and auditing contexts have not yet been fully explored. In a financial reporting setting, Hodge (2001) studied the effect of hyperlinking unaudited financial information to audited financial statements on investor judgments. He proposed that hyperlinking unaudited information to audited financial statements would increase the probability that investors would incorrectly attribute the source of the unaudited information to the audited financial statements. He found that the participants who reviewed hyperlinked materials erroneously classified more unaudited information as audited, and believed that the unaudited information was more credible, than did the individuals who received the information in hardcopy format. $\mathrm{He}$ also found that the higher credibility assessments in the hyperlinked condition resulted in higher judgments of the firm's earnings potential when compared to the judgments provided by those in the hardcopy condition (Hodge, 2001). Thus, the Hodge (2001) study provided evidence that changing the presentation format (web-based hyperlinks versus hardcopy) of financial statements can influence investors' judgments of a firm's earnings potential.

Within the context of auditing, Ricchiute (1984) conducted a study which examined the effect of presentation modality on auditor judgment. He assigned auditors to three groups: (1) visual, (2) auditory, and (3) visual/auditory. All groups were presented with two cases in which they were asked to assess the probability that an audit adjustment would be required. Group 1 received the two cases in typewritten form, group 2 heard the two cases as they were read aloud by the researcher, and group 3 received the two cases in both formats. Responses from group 1 (visual) and group 2 (auditory) differed significantly for both cases. Also, for one of the cases, group 1 (visual) responses were significantly different from those of group 3 (visual/auditory). Thus, this study provided evidence that altering the presentation modality of information can result in differences in auditor decision-making (Ricchiute, 1984). 


\subsection{Hypotheses}

The evidence items evaluated by auditors can be obtained in many formats and through different modalities. Some audit procedures generate visual evidence, others result in auditory evidence, and some evidence may be presented via multiple modalities. The media and modality through which evidence is obtained is often not within the auditor's control. The psychology literature has shown that using mixed presentation modalities (combined visual and auditory) results in better memory performance than does the use of a single modality (Mousavi et al., 1995; Tindall-Ford et al., 1997).

Hypothesis 1: Auditors who receive evidence items in mixed presentation modalities will commit fewer source monitoring errors than those who receive evidence in a single presentation modality.

The inferential value of audit evidence must be considered within the context of its source (Hirst, 1994). Research has shown that auditors are attentive to the sources of evidence when assessing the reliability of that evidence (Bamber, 1983; Rebele et al., 1988; Reimers and Fennema, 1999). However, Haynes (1999) stated that the management inquiry setting adds a level of uncertainty to the evaluation of evidence reliability. In this instance, auditors must consider two sources, management and the audit team member, when determining the extent to which evidence may be relied upon. She found that auditors focused more on the characteristics of the audit team and less on the diagnosticity of the evidence in the management inquiry scenario. She suggested that the auditors' shift in focus was a means of adjusting for the additional level of uncertainty.

Research has shown that presentation modality can negatively affect source monitoring accuracy. When a person commits a source monitoring error, he or she mistakenly attributes evidence from one source to another (Johnson et al., 1993). Auditors with lower source monitoring accuracy are less able to associate evidence items with the proper sources. Thus, as source monitoring errors occur, the credibility level of the wrong source is applied to the evidence item under evaluation. If the two sources have similar levels of credibility, then misattributing evidence from one source to the other should not impact auditors' reliability judgments. However, if the two sources have different credibility levels, these attribution errors should have an effect on auditors' evidence reliability judgments. Thus, in a management inquiry setting:

Hypothesis 2: When audit team members have similar credibility levels, source monitoring accuracy will have no effect on auditors' reliability judgments.

Hypothesis 3: When audit team members have different credibility levels, auditors with more (less) accurate source monitoring will produce lower (higher) evidence reliability judgments when the audit team member providing the evidence has lower credibility.

\section{Methodology}

\subsection{Task}

When conducting a management inquiry, the team member who had direct contact with management communicates management's responses to the in-charge auditor. The format of this communication (e.g. oral or written) depends upon the circumstances at that time. After receiving the communication, the in-charge auditor must evaluate the appropriateness of the information provided by the team member, determine the proper course of action, and document the all of the information related to the inquiry in the working papers. The task used in the present study was designed to address this management inquiry scenario.

Participants were asked to take on the role of an in-charge (senior) auditor. They were provided with the background, product line information, and selected financial data for a fictitious client firm. Participants were also given the descriptions of two audit team members. The case described an unexpected increase in the client's gross margin and asked the participants to read a memorandum suggesting that the firm's inventory may be overstated. All of this information was presented in a written format and participants were allowed access to it while making the requested judgments.

For participants in all conditions, the source of the inventory overstatement explanation was described as being of high credibility. (Note 1) This person was described as an experienced audit staff member who was soon expected to be promoted to audit senior. The case also stated that the participant had worked with this person several times in the past and had been impressed with his performance. After reading this information, participants assessed the likelihood that the gross margin was fairly stated using a seven-point Likert-type scale ( 1 = 'Not at All Likely' and 7 $=$ 'Extremely Likely'). 
Next, each participant received another set of information from the second member of the audit team. Participants received this information in either auditory or visual modality and the team member's credibility was manipulated to be either high or low. The source in the 'high' credibility condition was described as an audit manager who is known to be very knowledgeable and thorough. In the 'low' credibility condition, the source was a newly-hired staff auditor who had graduated from school one month ago. The individual had only worked one audit job prior to the current one and the feedback on his performance was that he had a lot to learn.

The case materials indicated that the information being presented by the second source had been obtained from the controller of the client firm. This team member provided a non-error explanation for the fluctuation. Specifically, he stated that a sales mix change had caused the increase in gross margin. Thus, the second explanation conflicted with the first explanation. In addition, the case materials contained enough information to allow the participants to determine that the sales mix change did not fully explain the fluctuation (the change in sales mix accounted for only 41 percent of the increase in gross margin). (Note 2) The sales mix change was, therefore, not the primary cause of the increased gross margin. The sales mix explanation was the same in all experimental conditions.

After receiving the second explanation, participants completed a distracter task and were then asked to provide another assessment of the likelihood of a fairly-stated gross margin. They were also asked to assess the reliability of the evidence provided by the second source on a seven-point Likert-type scale $(1=$ 'Not at All Reliable' and $7=$ 'Extremely Reliable'). The final section was a thirty-item recognition test. Twenty of the items had been included in the materials provided by the two audit team members and ten items were 'new' (not stated by either source). Participants were to determine whether each item had been 'explicitly stated' by either source. If so, they were to identify that source; if not, they were to mark the item was 'new.' (Note 3)

\subsection{Experimental Design}

This study employed a $2 \times 2$ design with between-subjects manipulations and random assignment. The two independent variables were presentation modality and source credibility. Presentation modality (PM) was manipulated as SAME PM (both evidence items were visual) or MIXED PM (one item was visual and one was auditory). Source credibility (SC) was manipulated as SAME SC (both sources were of high credibility) or MIXED SC (the first source was of high credibility while the second was low). These manipulations produced four cells as shown in Figure 1.

In order to ensure that participants were not referring to the evidence items as they completed the recognition test, they were instructed to place completed sections of the study into an envelope. Auditory materials were presented to the MIXED PM participants via audio CD. In preparing the CD, an American male adult read the memorandum information verbatim into a recording device. This ensured that the information presented in the visual and auditory treatments was identical. The auditory portion of the study was described to the participants as a voice-mail message.

This study focused on two dependent variables: (1) source monitoring accuracy; and (2) assessed reliability of the second evidence item. Source monitoring accuracy was measured as the number of correct responses to the twenty 'old' items on the recognition test. (Note 4) The assessed reliability of the second evidence item was measured on the seven-point Likert-type scale described above.

\subsection{Participants}

Ninety-one practicing auditors participated in this study. Descriptive statistics are displayed in Table 1. Fifty-one of the auditors were male and forty were female. The participants had an average of 3.55 years of auditing experience and had been working for their current firms for an average of 3.05 years.

The majority of the participating auditors (66 percent) were employed by a Big 4 audit firm. For these participants, the study took place at a national training session for in-charge auditors. The remaining 34 percent were employed by local or regional firms in the southeastern United States. These auditors completed the study in their respective offices. Sixty-two of the participants were licensed CPAs and 86 percent of the participants identified themselves as audit seniors. The thirteen non-senior auditors were employed by local or regional firms.

Prior research has shown that auditor seniors are appropriate participants for experimental tasks involving the use of analytical procedures during the planning stages of the audit (Abdolmohammadi, 1999; Hirst and Koonce 1996). In addition, professional experience has not been shown to significantly affect auditor judgments in tasks similar to the one used in the present study (J. C. Anderson et al., 2003; U. L. Anderson and Koonce, 1998). Thus, audit seniors were recruited for this study. 


\section{Results}

Two tests for normality were performed on this data set: Kolmogorov-Smirnov and Shapiro-Wilk. Both sets of test statistics were statistically significant for the dependent variables, indicating that the data were not normally distributed. Hence, the non-parametric Mann-Whitney (MW) test was used for testing the hypothesis in this study.

\subsection{Manipulation Checks}

No manipulation checks were performed for the PM manipulation because the participants either saw or heard the second set of evidence. This was a sensory manipulation only, and did not require participants' judgment to be effective. To test the effectiveness of the SC manipulation, participants were asked to assess the credibility of the second source on a seven-point Likert-type scale $(1=$ 'Not at All Credible' and $7=$ 'Extremely Credible'). The means were 5.31 and 4.70 for the SAME SC and MIXED SC groups respectively.

The MW test was performed on the mean ranks of 52.83 and 39.32 for the SAME SC and MIXED SC groups respectively. Testing indicated that the mean rank for the MIXED SC group was significantly lower than that of the SAME SC group $(U=727.50, p=0.01)$. For comparison, an ANOVA was also performed. Results indicated that the mean credibility assessment for the MIXED SC group was significantly lower than that of the SAME SC group (F= $6.42, \mathrm{p}=0.01$ ). Thus, the source credibility manipulation was considered to be effective.

\subsection{Source Monitoring Accuracy}

Hypothesis 1 predicted that auditors receiving audit evidence via mixed (visual and auditory) modalities would be more accurate in identifying the evidence sources than would auditors receiving the evidence via a single (visual) modality. The cell and margin means are displayed in Table 2 and cell means are shown graphically in Figure 2.

The mean ranks and results of the MW test performed on the PM variable are displayed in Table 3. Ranks of 40.21 (SAME PM) and 50.96 (MIXED PM) were compared for equality. The resulting U-statistic of 786.00 is statistically significant $(p=0.03)$, indicating that the MIXED PM group displayed higher source monitoring accuracy than did the SAME PM group. This result supports Hypothesis 1. An ANOVA was performed for comparison. The PM variable showed a significant main effect $(\mathrm{F}=5.52, \mathrm{p}=0.02)$. The $\mathrm{PM} \times \mathrm{SC}$ interaction was not significant $(\mathrm{F}=0.23$, $\mathrm{p}=1.64)$.

\subsection{Reliability Judgments}

The two hypotheses relating to the participants' reliability judgments were based on source monitoring accuracy. In Hypothesis 1, PM was shown to have a significant effect on auditors' source monitoring accuracy. Thus, PM was used as a proxy for source monitoring accuracy in testing Hypotheses 2 and 3. Given the results of Hypothesis 1, auditors in the MIXED PM group displayed higher source monitoring accuracy than did the auditors in the SAME PM group. The auditors' reliability assessments are presented in Table 4 and graphically in Figure 3.

Hypothesis 2 predicted that source monitoring accuracy would have no significant effect on auditors' reliability judgments when the sources had similar credibility levels. This analysis focused on the SAME SC condition in which both sources were described as being of high credibility (Table 4, Panel A). Since the sources in this condition have similar credibility levels, misattributing evidence from one source to the other should have no effect on auditors' judgments of the reliability of the evidence they provided. As expected, the results showed that source monitoring accuracy did not have a significant effect on auditors' assessed reliability in this condition $(U=207.50, p=0.15)$. Test results are presented in Table 5.

Hypothesis 3 predicted that auditors who displayed higher (lower) source monitoring accuracy would produce lower (higher) reliability judgments when the source of the evidence was of lower credibility. This analysis focused on the MIXED SC condition in which the second source was described as having lower credibility than the first source. The results of the MW test performed on these data are shown in Table 5. The U-statistic of 192.00 reveals that the mean ranks of the reliability assessments made by the auditors in the SAME PM group (25.86) were significantly higher (p $=0.05)$ than those in the MIXED PM group (20.68). Hypothesis 3 was supported. The results of this test imply that the auditors who were less accurate in identifying the sources of evidence considered the evidence obtained from a less-credible source to be of higher reliability than did the auditors who were more accurate in identifying evidence sources.

\subsection{Post-hoc Analysis}

Note-taking occurs in numerous everyday situations. The process involves the recording of information obtained from one or more sources. The writing of notes produces an external memory which can be used in future planning, learning, or thinking (Piolat et al., 2005). Note-taking serves two cognitive functions: storage and encoding (Kiewra 
et al., 1991). Research in this area has shown that the act of taking notes increases cognitive effort (Piolat et al., 2005) and recall accuracy (Middendorf and Macan, 2002).

The present study investigates whether evidence presented in a single modality produces different audit judgments than evidence presented in mixed modalities. If participants in this study were permitted to take notes while listening to the audio $\mathrm{CD}$, the result would be the creation of a visual stimulus in addition to the auditory stimulus. By contrast, not permitting participants to take notes might have caused them to question why they were being prevented from engaging in an activity that they normally perform when listening to voice messages in their daily lives. Such questioning could lead to demand effects.

For those in the MIXED PM conditions, taking notes during the auditory portion would still yield mixed presentation modalities. Also, any notes taken during the experiment were unavailable for review during the recognition test. For these reasons, participants were not barred from taking notes if they chose to do so.

Each MIXED PM experimental packet was visually examined to determine whether or not the auditor had taken notes. The NOTES variable was coded as 1 for 'yes' and 2 for 'no.' (Note 5) Of the forty-nine auditors in the MIXED PM condition, twenty-three took notes during the auditory portion of the study. Table 6 displays the mean source monitoring scores for auditors who did and did not take notes. The MW test compared the mean ranks of the source monitoring scores to determine whether or not note-taking had an effect on auditors' source monitoring accuracy. Results are presented in Table 7.

The results indicate that the auditors who took notes during the auditory portion of the study were more accurate in their source monitoring than were the auditors who did not take notes $(\mathrm{U}=194.00, \mathrm{p}=0.01)$. This finding implies that taking notes may improve source monitoring accuracy for auditors receiving auditory evidence.

\section{Discussion}

This study contributes to the audit literature in several ways. First, recent advances in cognitive psychology research allow for the formation of directional hypotheses. Ricchiute (1984) tested for significant differences in audit decisions across presentation modalities. The present study extends his research by hypothesizing, and finding, significantly higher source monitoring accuracy under mixed modality conditions along with a significantly lower assessment of reliability for evidence obtained from a less-credible source.

The second extension relates to the MIXED PM manipulation. In Ricchiute (1984), the visual/auditory group received both printed material and a verbal reading of that same information. Thus, participants in the visual/auditory treatment received the information twice. In the present study, participants in the MIXED PM condition were given two separate evidence sets in different modalities (one visual, one auditory), and each evidence set was presented once. Thus, the modality manipulation in the present study more closely resembles the auditors' evidence collection process.

Third, consistent with Ricchiute (1984), results of the present study indicate that auditor judgment may be affected by presentation modality. The audit decision-making literature has 'systematically overlooked auditory and visual/auditory presentation modes, thereby assuming implicitly that task presentation mode does not impact a subject's decisions' (p. 341). The combined results of these two studies imply that audit researchers should consider whether all-visual instruments may either weaken results or threaten external validity (Ricchiute 1984).

Fourth, the present study extends Haynes (1999) which investigated auditors' evaluation of evidence obtained via management inquiry. Consistent with Haynes (1999), auditors in the present study who were more accurate in their source monitoring appeared to base their evidence reliability judgments on the qualifications of the audit team member who communicated the information obtained from management. This occurred even though the information presented by the second source was not sufficient to explain the higher gross margin. Haynes (1999) suggested that the multiple levels of uncertainty (the credibility of both the audit team member and that of client management) may cause auditors to focus on the team member (as a source) rather than focusing on the diagnosticity of the evidence. This is a potentially problematic issue that should be explored in a future research study.

The modality effect identified in this study may also impact audit documentation. For example, the completeness of the working papers reviewed by the audit partner depends on the audit senior's memory for the evidence gathered during the audit (Ricchiute, 1999). Proper documentation is necessary to ensure that audit objectives were achieved (Florea and Florea, 20111). Thus, if the audit senior incorrectly identifies the source(s) of evidence and, as a result, includes inaccurate documentation in the working paper file, the engagement partner's judgments will be based on faulty information. As a result, the partner may form incorrect conclusions about the financial statements. Investigating this potential result would be a logical extension of this study. 
As noted earlier, ten 'new' items were included on the recognition test. These were items that did had appeared anywhere in the case materials. No between-group difference was expected for these items, but PM was found to have a significant effect. While not hypothesised to do so, the different presentation modalities may have also led some auditors to make inferences when faced with items which had not been encountered previously (Moeckel and Plumlee, 1989). This potential explanation can be examined in a future study.

Optimally, the constructs and hypothesised connections in the present study would have been presented in the form of a path diagram and tested using path analysis. However, because each construct was based on a single measure, such analysis was not possible. Going forward, the questions addressed in this study can be examined further by designing an experiment that allows for path analysis to be performed.

\section{Conclusion}

This study does not examine how presentation modality may influence order effects. As stated in Penney (1975), research on modality effects has provided evidence that auditory stimuli tend to result in more recency effects than do visual stimuli. In addition, prior research on auditor memory has shown that recency effects can influence auditor judgments (Asare, 1992). The potential interaction between presentation modality and order effects on auditor judgment is another area for future research.

Future research can also examine the impact of different media on auditor judgments. Technology has allowed for information to be obtained via email, text messaging, video conferencing, instant-messaging, etc. The findings in Hodge (2001) imply that the choice of media may play a role in auditors' judgments.

In addition, other factors influencing source monitoring accuracy can be examined. Stress and/or attention-splitting are possible avenues for further study in this area. Cognitive psychologists have found that these factors can negatively affect source monitoring accuracy (Jacoby, et al., 1989; Kelley \& Lindsay, 1993). As a result of time pressure and multi-client work loads, auditors work under conditions of stress and divided-attention on a regular basis. These factors may also affect their source monitoring accuracy and their subsequent credibility and/or reliability judgments.

\section{Acknowledgements}

This paper is based on my dissertation and I am grateful for the assistance provided by my committee at Florida State University: Bud Fennema (Chair), Allen Blay, Greg Gerard, Colleen Kelley, and Richard Dusenbury (ret.). I also thank Jessen Hobson, Sandra Goldson, Kenya Ayers, Michael Borkowski, Andre Holmes, Kyle Meyer, and the firms and auditors who participated in this study. I extend additional thanks to Dorla Evans, Chris Allport, Helen Brown-Liburd, Ena Rose-Green, anonymous reviewers, and the participants in the 2010 AAA Diversity Section meeting for their helpful comments. Finally, I thank the KPMG Foundation, the Florida Education Fund, and the AICPA for their financial support.

\section{References}

Abdolmohammadi, M. J. (1999). A comprehensive taxonomy of audit task structure, professional rank, and decision aids for behavioral research. Behavioral Research in Accounting 11:51-92.

Anderson, J. C., Moreno, K. K., and Miller, J. M. (2003). The effect of client vs. decision aid as a source of explanations upon auditors' sufficiency judgments: A research note. Behavioral Research in Accounting 15:1-11. http://dx.doi.org/10.2308/bria.2003.15.1.1

Anderson, U. L., and Koonce, L. (1998). Evaluating the sufficiency of causes in audit analytical procedures. Auditing: A Journal of Practice and Theory 17 (1):1-12.

Anderson, U. L., Koonce, L., and Marchant, G. (1994). The effects of source-competence information and its timing on auditors' performance of analytical procedures. Auditing: A Journal of Practice and Theory 13 (1):137-148.

Asare, S. K. (1992). The auditor's going-concern decision: Interaction of task variables and the sequential processing of evidence. Accounting Review 67 (2):379-393.

Ashton, A. H., and Ashton, R. H (1988). Sequential belief revision in auditing. Accounting Review 63 (4):623-641.

Bamber, E. M. (1983). Expert judgment in the audit team: A source reliability approach. Journal of Accounting Research 21 (2):396-412. http://dx.doi.org/10.2307/2490781

Corballis, M. C. (1966). Rehearsal and decay in immediate recall of visually and aurally presented items. Conadian Journal of Psychology 20:43-51. http://dx.doi.org/10.1037/h0082923 
Debreceny, R. S., and Gray, G. L. (2011). Data mining of electronic mail and auditing: A research agenda. Jounal of Information Systems, 25(2):195-226. http://dx.doi.org/10.2308/isys-10167

Florea, R., and Florea, R. (2011). Audit techniques and audit evidence. Economy Transdisciplinarity Cognition, $\mathrm{XIV}(1): 350-358$.

Frick, R. W. (1984). Using both an auditory and visual short-term store to imcrease digit-span. Memory \& Cognition 12:507-514. http://dx.doi.org/10.3758/BF03198313

Gamble, K. F. (2010). The effect of presentation modality on source monitoring accuracy: Implications for auditors' reliability judgments and the planned extent of audit procedures. Unpublished doctoral dissertation, Florida State University.

Hashtroudi, S., Johnson, M. K., and Chrosniak, L. D (1989). Aging and source monitoring. Psychology and Aging 4 (1):106-112. http://dx.doi.org/10.1037//0882-7974.4.1.106

Haynes, C. M. (1999). Auditors' evaluation of evidence obtained through management inquiry: A cascaded-inference approach. Auditing: A Journal of Practice and Theory 18(2):87-104. http://dx.doi.org/10.2308/aud.1999.18.2.87

Hirst, D. E. (1994). Auditors' sensitivity to source reliability. Journal of Accounting Research 32 (1):113-126. http://dx.doi.org/10.2307/2491390

Hirst, D. E., and Koonce, L. (1996). Audit analytical procedures: A field investigation. Contemporary Accounting Research 13 (2):457-486. http://dx.doi.org/10.1111/j.1911-3846.1996.tb00511.x

Hodge, F. D. (2001). Hyperlinking unaudited information to audited financial statements: Effects on investor judgments. Accounting Review 76 (4):675-691. http://dx.doi.org/10.2308/accr.2001.76.4.675

Jacoby, L. L., Woloshyn, V. W., and Kelley, C. M. (1989). Becoming famous without being recognized: Unconscious influences of memory produced by dividing attention. Journal of Experimental Psychology: General 118 (2):115-125. http://dx.doi.org/10.1037//0096-3445.118.2.115

Johnson, M. K., Hashtroudi, S., and Lindsay, D. S. (1993). Source monitoring. Psychological Bulletin 114 (1):3-28. http://dx.doi.org/10.1037//0033-2909.114.1.3

Kelley, C. M., and Lindsay, D. S. (1993). Remembering mistaken for knowing: Ease of retrieval as basis for confidence in answers to general knowledge questions. Journal of Memory and Language 32:1-24. http://dx.doi.org/10.1006/jmla.1993.1001

Kiewra, K. A., DuBois, N. F.,Christian. D., McShane, A., Meyerhoffer, M., and Roskelley, D. (1991). Note-taking functions and techniques. Journal of Educational Psychology 82:240-245. http://dx.doi.org/10.1037//0022-0663.83.2.240

Kirsner, K., and Craik, F. I. (1971). Naming and decision process in short-term recognition memory. Journal of Experimental Psychology 88 (2):149-157. http://dx.doi.org/10.1037/h0030916

Knechel, W. R., and Messier, W. F. (1990). Sequential auditor decision making: Information search and evidence evaluation. Contemporary Accounting Research 6(2)' http://dx.doi.org/10.1111/j.1911-3846.1990.tb00765.x

Laughery, K. R., and Pinkus, A. L. (1966). Short-term memory: Effects of acoustic similarity, presentation rate, and presentation mode. Psychonomic Science 6:285-286.

Lindsay, D. S., and Johnson, M. K. (2000). False memories and the source monitoring framework: Reply to Reyna and Lloyd (1997). Learning and Individual Differences 12:145-161. http://dx.doi.org/10.1016/S1041-6080(01)00035-8

Lindsay, D. S., Johnson, M. K., and Kwon, A. (1991). Developmental changes in memory source monitoring. Journal of Experimental Child Psychology 52:297-318. http://dx.doi.org/10.1016/0022-0965(91)90065-Z

Margheim, L. (1986). Further evidence on external auditors' reliance on internal auditors. Journal of Accounting Research 24 (1):194-205. http://dx.doi.org/10.2307/2490813

Martin, M. (1980). Attention to words in different modalities: Four-channel presentation with physical and semantic selection. Acta Psychologica 44:99-115. http://dx.doi.org/10.1016/0001-6918(80)90061-X

Middendorf, C. H., and Macan, T. H. (2002). Note-taking in the employment interview: effects on Recall and judgments. Journal of Applied Psychology 87 (2):293-303. http://dx.doi.org/10.1037//0021-9010.87.2.293 
Moeckel, C. L. and Plumlee, R. D. (1989). Auditors' confidence in recognition of audit evidence. Accounting Review 64(4): 653-666.

Mousavi, S. Low, Y., R., and Sweller, J. (1995). Reducing cognitive load by mixing auditory and visual presentation modes. Journal of Educational Psychology 87 (2):319-334. http://dx.doi.org/10.1037//0022-0663.87.2.319

Murdock, B. B. (1968). Modality effects in short-term memory: Storage or retrieval. Journal of Experimental Psychology 77:79-86. http://dx.doi.org/10.1037/h0025786

Penney, C.G. (1975). Modality effects in short-term verbal memory. PsychologicalBulletin, 82, 68-84. http://dx.doi.org/10.1037/h0076166

Penney, C. G. (1989). Modality effects and the structure of short-term verbal memory. Memory \& Cognition 17 (4):398-422. http://dx.doi.org/10.3758/BF03202613

Piolat, A., Oliver, T., and Kellogg, R. T. (2005). Cognitive effort during note taking. Applied Cognitive Psychology 19:291-315. http://dx.doi.org/10.1002/acp.1086

PCAOB, (2010). Audit Standard No. 15: Audit Evidence. Retrieved from http://pcaobus.org/Standards/Auditing/Pages/Auditing_Standard_15.aspx on March 16, 2011.

Rebele, J. E., Heintz, J. A., and Briden, G. E. (1988). Independent auditor sensitivity to evidence reliability. Auditing. A Journal of Practice and Theory 8 (1):43-52.

Reimers, J. L., and Fennema, M. G. (1999). The audit review process and sensitivity to information source objectivity. Auditing: A Journal of Practice and Theory 18 (1):117-123. http://dx.doi.org/10.2308/aud.1999.18.1.117

Ricchiute, D. N. (1984). An empirical assessment of the impact of alternative task presentation modes on decision-making research in auditing. Journal of Accounting Research 22(1) 341-350. http://dx.doi.org/10.2307/2490715

Ricchiute, D. N. (1999). The effects of audit seniors' decisions on working paper documentation and on partners' decisions. Accounting, Organizations and Society 24:155-171. http://dx.doi.org/10.1016/S0361-3682(98)00029-4

Tindall-Ford, Chandler, S., P., and Sweller, J. (1997). When two sensory modes are better than one. Journal of Experimental Psychology: Applied 3 (4):257-287. http://dx.doi.org/10.1037//1076-898X.3.4.257

Wright, W. E., and Berger, L. (2011). Fraudulent management explanations and the impact of alternative presentations of client business evidence. Auditing: A Journal of Practice and Theory. 30(2):153-171. http://dx.doi.org/10.2308/ajpt-50010

\section{Notes}

Note 1. Following past literature, credibility was described in terms of competence throughout this study (see Anderson et al., 1994; Bamber,1983; Margheim, 1986).

Note 2. See U. L. Anderson and Koonce (1998).

Note 3. See Moeckel and Plumlee (1989).

Note 4. The ten 'new' items were included on the recognition test for control purposes. These items are discussed in a later section of the paper

Note 5. The NOTES variable for those in the SAME PM group was coded as 0 for 'not applicable.' Participants in this group were excluded from the testing. 
Table 1. Descriptive Statistics

\begin{tabular}{|c|c|c|c|}
\hline \multicolumn{4}{|c|}{ Panel A: Demographics } \\
\hline \multirow[t]{3}{*}{ Gender: } & Male & 51 & $(56 \%)$ \\
\hline & Female & 40 & $(44 \%)$ \\
\hline & & 91 & \\
\hline \multirow[t]{4}{*}{ Age (years): } & Minimum & 23.00 & \\
\hline & Maximum & 46.00 & \\
\hline & Mean & 28.00 & \\
\hline & Std. Dev. & 4.47 & \\
\hline \multicolumn{4}{|l|}{ Panel B: Experience } \\
\hline \multirow[t]{3}{*}{ Type of Firm: } & 'Big 4' & 60 & $(66 \%)$ \\
\hline & Local/Regional & 31 & $(34 \%)$ \\
\hline & & 91 & \\
\hline \multirow[t]{4}{*}{ Title: } & Staff & 4 & $(4 \%)$ \\
\hline & Senior & 78 & $(86 \%)$ \\
\hline & Supervisor/Manager & 9 & $(10 \%)$ \\
\hline & & 91 & \\
\hline Total Audit & Minimum & 0.50 & \\
\hline \multirow[t]{3}{*}{ Experience (years): } & Maximum & 4.83 & \\
\hline & Mean & 3.55 & \\
\hline & Std. Dev. & 1.80 & \\
\hline Time with Current & Minimum & 0.50 & \\
\hline \multirow[t]{3}{*}{ Firm (years): } & Maximum & 1.83 & \\
\hline & Mean & 3.05 & \\
\hline & Std. Dev. & 1.35 & \\
\hline \multirow[t]{3}{*}{ Licensed CPA?: } & Yes & 62 & $(68 \%)$ \\
\hline & No & 29 & $(32 \%)$ \\
\hline & & 91 & \\
\hline
\end{tabular}

The table above summarizes demographic information about the participants in this study. 
Table 2. Source Monitoring Accuracy ${ }^{\mathrm{a}}$ - Means (Standard Deviations)

\begin{tabular}{|c|c|c|}
\hline Panel A: & & Cell Means \\
\hline Cell 1 (SAME SC x SAME PM) ${ }^{b}$ & $\mathrm{n}=21$ & $13.00(3.83)$ \\
\hline Cell 2 (SAME SC x MIXED PM) & $\mathrm{n}=24$ & $14.95(2.85)$ \\
\hline Cell 3 (MIXED SC x SAME PM) & $\mathrm{n}=21$ & $13.38(3.60)$ \\
\hline Cell 4 (MIXED SC x MIXED PM) & $\mathrm{n}=25$ & $14.68(2.93)$ \\
\hline Panel B: & & Margin Means \\
\hline SAME SC ${ }^{\mathrm{c}}$ & $\mathrm{n}=45$ & $14.04(3.45)$ \\
\hline MIXED SC ${ }^{\mathrm{d}}$ & $\mathrm{n}=46$ & $14.09(3.28)$ \\
\hline SAME PM ${ }^{\mathrm{e}}$ & $\mathrm{n}=42$ & $13.19(3.68)$ \\
\hline MIXED PM ${ }^{\mathrm{f}}$ & $\mathrm{n}=49$ & $14.82(2.86)$ \\
\hline Panel C: & & Overall \\
\hline All Data & $\mathrm{n}=91$ & $14.07(3.35)$ \\
\hline \multicolumn{3}{|l|}{ a Number of correct responses on the twenty 'OLD' test items } \\
\hline \multicolumn{3}{|l|}{$b S C=$ Source Credibility $; P M=$ Presentation Modality } \\
\hline \multicolumn{3}{|l|}{ c Both sources are of high credibility } \\
\hline \multicolumn{3}{|l|}{$d$ First source is of high credibility; second source is of low credibility } \\
\hline \multicolumn{3}{|l|}{ e Both evidence items are visual } \\
\hline fFirst evidence item is visual; second evidence item is auditory & & \\
\hline
\end{tabular}

The above table contains the cell and margin means for source monitoring accuracy $(\max =20)$.

Table 3. Hypothesis 1

\begin{tabular}{lcc}
\hline Panel A: & & Mean Ranks \\
\hline SAME PM $^{\mathrm{a}}$ & $\mathrm{n}=42$ & 40.21 \\
MIXED PM $^{\mathrm{b}}$ & $\mathrm{n}=49$ & 50.96 \\
\hline & & Mann-Whitney \\
Panel B: & & Results \\
\hline Mann-Whitney U & 786.00 \\
Sig. (1-tailed) & $0.03^{*}$ \\
\hline DV = Source monitoring accuracy on 'OLD' items & \\
a Both evidence items are visual & \\
b First evidence item is visual; second evidence item is auditory & \\
\hline
\end{tabular}

The above table contains the results of the Mann-Whitney test of differences in source monitoring accuracy between the SAME and MIXED PM treatment groups. 
Table 4. Reliability Assessments ${ }^{\mathrm{a}}$ - Means (Standard Deviations)

\begin{tabular}{|c|c|c|}
\hline Panel A: & & SAME SC ${ }^{\text {b }}$ \\
\hline SAME PM (Lower Accuracy) ${ }^{\mathrm{e}}$ & $\mathrm{n}=21$ & $4.62(1.28)$ \\
\hline MIXED PM (Higher Accuracy) ${ }^{\mathrm{f}}$ & $\mathrm{n}=24$ & $4.17(1.44)$ \\
\hline SAME SC Mean & $\mathrm{n}=45$ & $4.38(1.37)$ \\
\hline Panel B: & & MIXED SC ${ }^{c}$ \\
\hline SAME PM (Lower Accuracy) ${ }^{\mathrm{e}}$ & $\mathrm{n}=21$ & $4.29(1.31)$ \\
\hline MIXED PM (Higher Accuracy) ${ }^{\mathrm{f}}$ & $\mathrm{n}=25$ & $3.80(1.12)$ \\
\hline MIXED SC Mean & $\mathrm{n}=46$ & $4.02(1.22)$ \\
\hline Panel C: & & Overall \\
\hline All Data & $\mathrm{n}=96$ & $4.20(1.30)$ \\
\hline \multicolumn{3}{|c|}{ a Seven-point Likert-type scale: $1=$ 'Not at All Reliable' and $7=$ 'Extremely Reliable' } \\
\hline \multicolumn{3}{|c|}{ c First source is of high credibility; second source is of low } \\
\hline \multicolumn{3}{|l|}{ credibility } \\
\hline \multicolumn{3}{|l|}{ e Both evidence items are visual } \\
\hline \multicolumn{3}{|c|}{ f First evidence item is visual; second evidence item is auditory } \\
\hline
\end{tabular}

The above table presents the mean evidence reliability assessments provided by participating auditors.

Table 5. Hypotheses 2 and 3

\begin{tabular}{lcc}
\hline Panel A: Mean Ranks & SAME SC $^{\mathbf{c}}$ & MIXED SC $^{\mathbf{d}}$ \\
\hline Lower Accuracy $(S A M E ~ P M)^{\mathrm{a}}$ & 25.12 & 25.86 \\
& $\mathrm{n}=21$ & $\mathrm{n}=21$ \\
Higher Accuracy $(M I X E D P M)^{\mathrm{b}}$ & 21.15 & 20.68 \\
& $\mathrm{n}=24$ & $\mathrm{n}=25$ \\
\hline Panel B: Mann-Whitney Results & SAME SC & MIXED SC \\
\hline Mann-Whitney U & 207.50 & 192.00 \\
Sig. (1-tailed) & 0.15 & $0.05 *$ \\
& (Hypo 2) & (Hypo 3) \\
\hline
\end{tabular}

$\mathrm{DV}=$ Reliability of evidence received from second source

a Both evidence items are visual

$b$ First evidence item is visual; second evidence item is auditor

$c$ Both sources are of high credibility

$d$ First source - high credibility; second source - low credibility

The above table contains the results of the Mann-Whitney test of differences in evidence reliability assessments between the SAME and MIXED PM treatments within the SAME and MIXED SC conditions. 
Table 6. Note Taking a, ${ }^{\mathrm{a}}$ - Means (Standard Deviations)

Took Notes

Did Not Take Notes

Overall

DV = Source Monitoring Accuracy

a Number of correct responses on twenty-item recognition test.

$b$ Includes only those participants in the MIXED PM condition

The above table contains the mean source monitoring accuracy scores for auditors in the MIXED PM treatment who did and did not take notes during the auditory presentation.

Table 7. Post-hoc Analysis (Note-Taking)

\begin{tabular}{lcc}
\hline Panel A: & & Mean Ranks \\
\hline Took Notes & $\mathrm{n}=23$ & 29.57 \\
Did Not Take Notes & $\mathrm{n}=26$ & 20.96 \\
\hline & & Mann-Whitney \\
Panel B: & & Results \\
\hline Mann-Whitney U & & 194.00 \\
Sig. (1-tailed) & & $0.01^{* *}$ \\
\hline
\end{tabular}

$\mathrm{DV}=$ Source Monitoring Accuracy

The above table contains the results of the Mann-Whitney test of differences in source monitoring accuracy between the auditors in the MIXED PM condition who did and did not take notes during the auditory presentation. 


\begin{tabular}{|c|c|c|c|c|c|c|}
\hline \multirow[b]{3}{*}{ Cell 1} & \multicolumn{2}{|c|}{$1^{\text {st }}$ SOURCE * } & \multicolumn{2}{|c|}{$2^{\text {nd }}$ SOURCE } & \multicolumn{2}{|c|}{$2 \times 2$ DESIGN } \\
\hline & $\underline{\mathrm{SC}}$ & $\underline{\mathrm{PM}}$ & $\underline{\mathrm{SC}}$ & $\underline{\mathrm{PM}}$ & $\underline{\mathrm{SC}}$ & $\underline{\mathbf{P M}}$ \\
\hline & $\mathrm{H}$ & $\mathrm{V}$ & $\mathrm{H}$ & $\mathrm{V}$ & SAME & SAME \\
\hline Cell 2 & $\mathrm{H}$ & $\mathrm{V}$ & $\mathrm{H}$ & $\mathrm{A}$ & SAME & MIXED \\
\hline Cell 3 & $\mathrm{H}$ & $\mathrm{V}$ & $\mathrm{L}$ & $\mathrm{V}$ & MIXED & SAME \\
\hline Cell 4 & $\mathrm{H}$ & $\mathrm{V}$ & $\mathrm{L}$ & A & MIXED & MIXED \\
\hline
\end{tabular}

* Credibility and modality of the first source are held constant as high and visual respectively.

Key:

$H=$ High Source Credibility

$L=$ Low Source Credibility

$V=$ Visual Presentation Modality

$A=$ Auditory Presentation Modality

Figure 1. Cell Detail

The above figure contains the cell detail for the $2 \times 2$ research design.

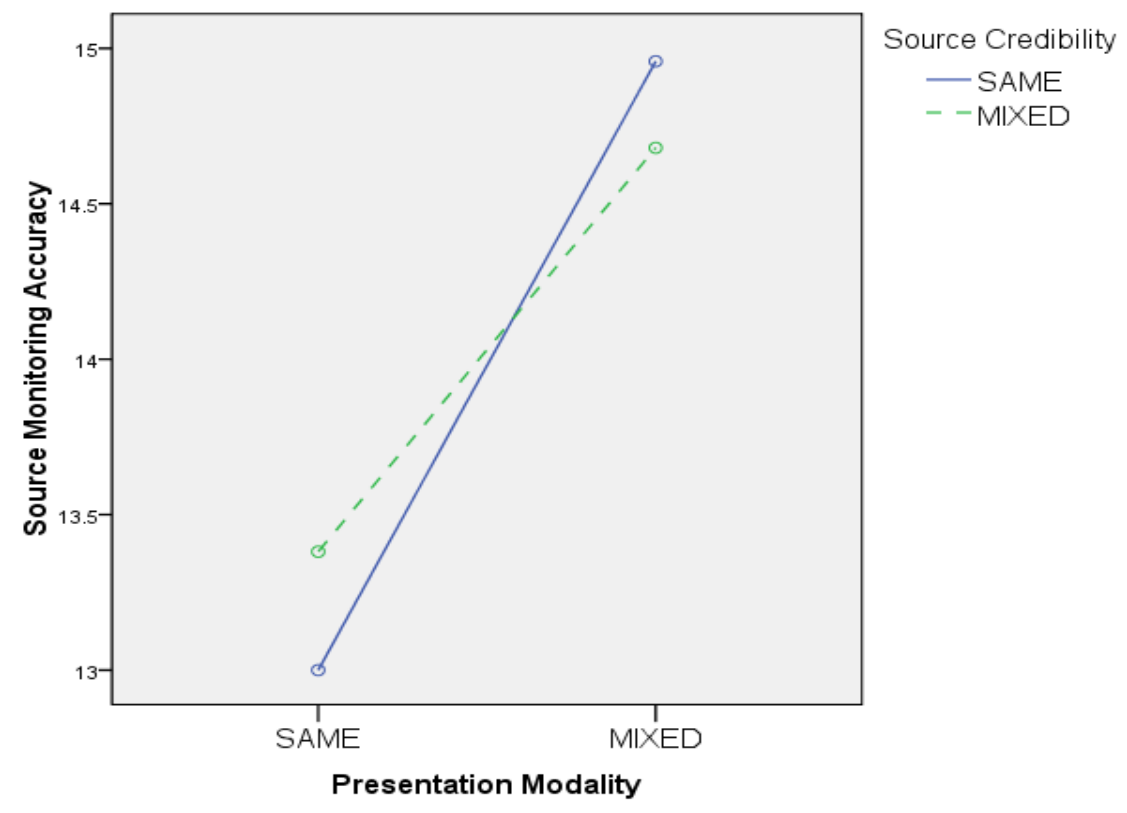

Figure 2. Source Monitoring Accuracy

The above figure displays the source monitoring accuracy cell means. 


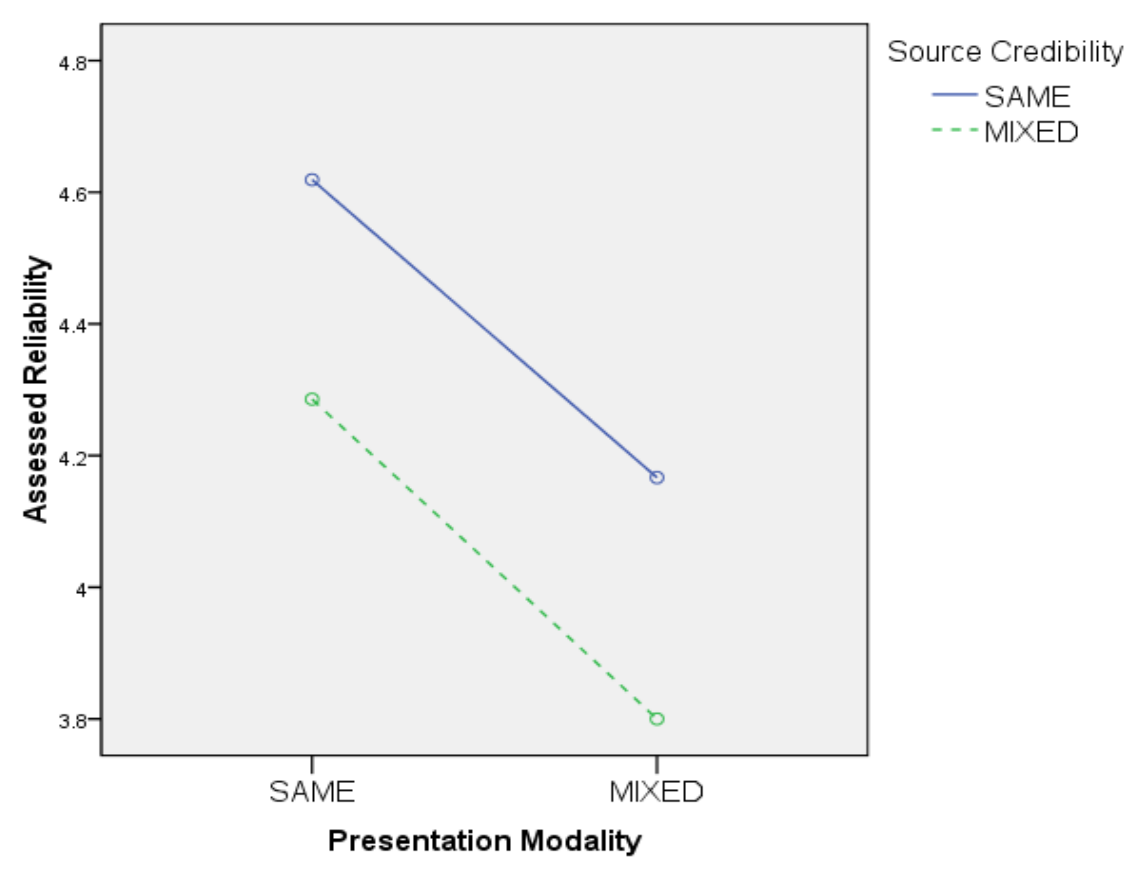

Figure 3. Assessed Reliability

The above figure displays the cell means for the auditors' reliability assessments. 